\title{
Les prénoms révolutionnaires à Dol-De-Bretagne
}

\section{Nadine Berthau}

\section{(2) OpenEdition}

\section{Journals}

\section{Édition électronique}

URL : https://journals.openedition.org/ahrf/1847

DOI : 10.4000/ahrf.1847

ISSN : 1952-403X

Éditeur :

Armand Colin, Société des études robespierristes

\section{Édition imprimée}

Date de publication : 1 décembre 2000

Pagination : 136

ISSN : 0003-4436

\section{Référence électronique}

Nadine Berthau, «Les prénoms révolutionnaires à Dol-De-Bretagne », Annales historiques de la

Révolution française [En ligne], 322 I octobre-décembre 2000, mis en ligne le 22 mars 2006, consulté le 24 avril 2022. URL : http://journals.openedition.org/ahrf/1847 ; DOI : https://doi.org/10.4000/ahrf. 1847

Ce document a été généré automatiquement le 24 avril 2022

Tous droits réservés 


\title{
Les prénoms révolutionnaires à Dol- De-Bretagne
}

\author{
Nadine Berthau
}

Acte de naissance de Brutus La Raison Espoir du Monde Coursin, à Dol-de-Bretagne, le 15 ventôse an II (5 mars 1794)

1 « Aujourd'hui quinze ventôse, l'an second de la République française une et indivisible, par devant moi, René-François-Timothée Juhel La plesse, élu le deux pluviôse pour rédiger les actes des naissances, mariages et décès des citoyens sont comparus JeanMathurin Coursin, chapelier âgé de vingt ans, domicilié en cette commune de Dol, rue de la Liberté, $n^{\circ} 22$, lequel était assisté de Jean-Charles Coursin, son frère germain, aussi chapelier, âgé de vingt et un ans, aussi domicilié dans notre commune et de Thomas Vaujois, cordonnier, âgé de trente-trois ans et dûment domicilié de Dol, rue de la Liberté, m'a déclaré à moi, officier public, que Marguerite Blin, son épouse en légitime mariage a accouché ce jour à une heure après midi en sa maison de la rue de la Liberté d'un enfant mâle auquel il a donné le prénom de Brutus La Raison Espoir du Monde. D'après ces déclarations et la présentation de l'enfant qui m'ont été faites, j'ai rapporté le présent acte sous la signature dudit Jean Mathurin-Coursin et desdits Coursin, oncle de l'enfant Vaujois et même du citoyen Jacques Le Brete et de la citoyenne Renant, épouse du citoyen Gautier, juge de paix de cette ville, présents et les tous témoins.

2 Fait en la maison commune de Dol lesdits jour et an que dessus, trois mots rayés nuls approuvés. "

Acte de naissance de Myrtil Jasmin Patriote Loncle, à Dol-de-Bretagne, le 27 prairial an II (15 juin 1794)

3 «Aujourd'hui vingt sept prairial, l'an second de la République française, une et indivisible, aux huit heures dudit jour, devant moi René-François-Thimotée Juhel La plesse, agent national et officier public de la commune de Dol, est comparu en la salle de la Maison Commune, Marie-Françoise Mondin, veuve Gilles Julien Bienvenu, sagefemme, domiciliée de Dol, âgée de cinquante-huit ans, assistée de Françoise-Jeanne Bienvenu, âgée de vingt et un ans, tailleuse et de Marguerite Domer, âgée de vingt-deux ans, lingère, femme du citoyen Jean Gilles Bienvenu, secrétaire de la municipalité de 
Dol, tous domiciliés de ladite commune, laquelle m'a déclaré que Jeanne Loncle, âgée de trente-trois ans, veuve de Mathurin Muguet, est accouchée aujourd'hui sur les deux heures et demie après-midi, dans sa demeure située rue de la Liberté, d'un enfant mâle, qu'elle m'a présenté et auquel elle a donné les prénoms de Mirtil-Jasmin Patriote, déclarant que ladite Jeanne Loncle n'est plus dans l'état du mariage depuis plusieurs années. D'après cette déclaration et la représentation de l'enfant, j'ai rédigé le présent acte que ladite et les deux témoins ont signé avec moi. Fait en la Maison Commune de Dol, les jours, mois et an susdits.»

\section{BIBLIOGRAPHIE}

Nadine Berthau, Cornélie, Jasmin, Espoir du Monde, Les prénoms révolutionnaires en Ille-et-Vilaine (1790-1795), maîtrise Rennes 2, 1995, dactyl., annexe 30, documents 4 et 8.) 